Provided for non-commercial research and education use. Not for reproduction, distribution or commercial use.

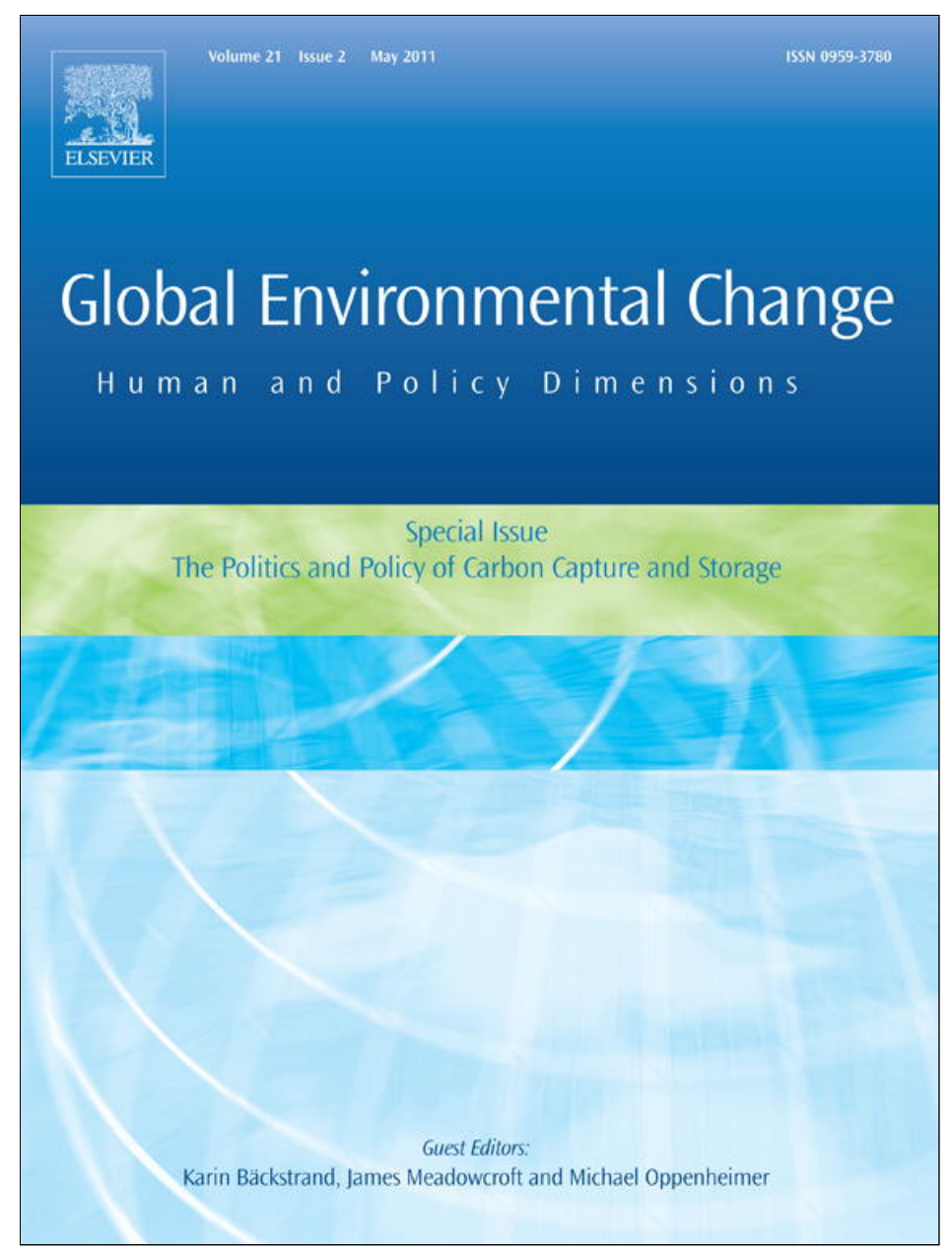

This article appeared in a journal published by Elsevier. The attached copy is furnished to the author for internal non-commercial research and education use, including for instruction at the authors institution and sharing with colleagues.

Other uses, including reproduction and distribution, or selling or licensing copies, or posting to personal, institutional or third party websites are prohibited.

In most cases authors are permitted to post their version of the article (e.g. in Word or Tex form) to their personal website or institutional repository. Authors requiring further information regarding Elsevier's archiving and manuscript policies are encouraged to visit:

http://www.elsevier.com/copyright 


\title{
Characterizing the international carbon capture and storage community
}

\author{
Jennie C. Stephens ${ }^{\mathrm{a}, *}$, Anders Hansson ${ }^{\mathrm{b}, \mathrm{c}}$, Yue Liu ${ }^{\mathrm{a}}$, Heleen de Coninck ${ }^{\mathrm{d}}$, Shalini Vajjhala ${ }^{\mathrm{e}}$ \\ ${ }^{a}$ Environmental Science E Policy Program, International Development, Community and Environment (IDCE), Clark University, 950 Main Street, Worcester, MA 01610, USA \\ ${ }^{\mathrm{b}}$ Centre for Climate Science and Policy Research (CSPR), Linköping University, SE-601 74 Norrköping, Sweden \\ ${ }^{\mathrm{c}}$ Department of Technology and Social Change, Linköping University, SE-58183 Linköping, Sweden \\ ${ }^{\mathrm{d}}$ Energy Research Centre of the Netherlands, Unit Policy Studies, Radarweg 60, 1043 NT Amsterdam, Netherlands \\ ${ }^{\mathrm{e}}$ Resources for the Future (RFF), 1616 P Street NW, Washington, DC 20036, USA
}

\section{A R T I C L E I N F O}

\section{Article history:}

Received 28 April 2010

Received in revised form 10 January 2011

Accepted 18 January 2011

Available online 18 February 2011

\section{Keywords:}

Carbon dioxide capture and storage (CCS)

Climate mitigation

Climate policy

Public perception

Risk perceptions

Epistemic communities

\begin{abstract}
A B S T R A C T
Carbon capture and storage (CCS) is a controversial climate change mitigation technology that has been receiving increased public and private investment over the past decade in several countries. During this time, a diverse international network of professionals focused on the advancement of CCS technology has emerged. Within this international CCS community, a shared perception of the value of advancing CCS technology is generally assumed, and this community has been influential in lobbying for increased support for the development of CCS in many countries and at the international level. The phenomenon of an apparently shared perspective within a specific community relates to Haas' (1992a) description of the evolution of an epistemic community, or a knowledge-based network of recognized experts who "not only hold in common a set of principled and causal beliefs but also have shared notions of validity and a shared policy enterprise". Understanding the extent to which a given community can be characterized as an epistemic community can provide insights about the effectiveness of its policy intervention, its association with the broader public, and the success of communicating the messages that it wants to convey. The goal of this research is to begin to explore the nature of the CCS community; to provide a preliminary characterization of the community, and to consider whether and in what ways the community might be considered to be an epistemic community or a compilation of multiple different epistemic communities. This characterization suggests that although the CCS community may be influencing decision-makers and successfully garnering political support for advancing CCS technology, a potential disconnect with the concerns of a broader public is deserving of more attention and social science research.
\end{abstract}

(c) 2011 Elsevier Ltd. All rights reserved.

\section{Introduction}

Carbon capture and storage (CCS) is an emerging climate change mitigation technology that has been gaining importance in both national and international policy agendas over the past decade (Coninck, 2010; IEA, 2008; IPCC, 2005, 2007; Meadowcroft and Langhelle, 2009). This attention has been associated with and fueled by an increase in both public and private investment in CCS (ACCSEPT, 2007; Climate Group et al., 2010; Global CCS Institute, 2009; Tjernshaugen, 2008; van Alphen et al., 2010) and an associated gradual but rapid increase in the number of individuals whose careers are focused on the advancement of this technology. ${ }^{1}$

\footnotetext{
* Corresponding author. Tel.: +1 508793 8846; fax: +1 5087938820 . E-mail addresses: jstephens@clarku.edu (J.C. Stephens), anders.n.hansson@liu.se (A. Hansson),yulie@clarku.edu (Y. Liu), deconinck@ecn.nl (H. de Coninck), shalinirff@gmail.com (S. Vajjhala).

${ }^{1}$ Exemplified by gradually increasing attendance numbers for the main international conference on CCS, the GHGT, which increased from about 250 in 1994 to 1600 in 2010
}

Communication among these individuals has created a diverse international network of professionals focused on the technology's advancement; in this paper, we refer to this network as the international CCS community. This community includes scientific and technical experts, as well as representatives from business, government, academia and non-governmental organizations.

The growth of the international CCS community over the past decade has been, at least in part, self-perpetuating, i.e., the community has effectively advocated for increased investment in CCS technology, which has resulted in growth in the number of individuals working on advancing CCS. Even though both the international CCS community and investment in CCS have increased, public awareness about CCS remains low (Reiner, 2008; Reiner et al., 2006). With the growth of CCS initiatives, however, controversy and public opposition to further advancement of CCS has become more visible (Van Noorden, 2010).

Public concern and opposition to CCS technology can be divided into two categories related to different perceived risks at global and local levels: (1) general opposition to the technology as an end-ofpipe, expensive climate mitigation option that is resource-intensive, 
promotes the use of fossil fuels, competes with renewable energy sources, and is technologically complex and environmentally risky and (2) project-specific opposition among communities that are confronted with planned projects and perceive local risks associated with those projects (Bielicki and Stephens, 2008; Wilson et al., 2003). The environmental community has been divided in their level of support for this technology (Wong-Parodi et al., 2008). Skepticism about the technology's potential to facilitate a transition away from fossil fuels is strong (Greenpeace International, 2008), but there are also environmental organizations that are highly supportive or accepting of CCS (e.g., World Wildlife Fund (WWF), Bellona, Natural Resources Defense Council). Project-specific opposition can be seen in various recent proposed CCS projects, such as Vattenfall's cancelled and postponed storage projects in Denmark and Germany (NyTeknik, 2009) and the cancelled Barendrecht project in the Netherlands (Feenstra et al., 2010; Van Noorden, 2010).

Given the potential for public opposition to influence the advancement of this technology, how the CCS community addresses concerns and critical perspectives impacts the extent and pace of the technology's development. Boundaries and limitations in energy professionals' capacity to consider different energy technology scenarios have been previously explored by several scholars, including the anthropologist Laura Nader. In the 1970s, Nader observed groups of energy technology experts and identified within these groups standardized thinking about the risks and potentials of specific energy technologies and a lack of respect for a diversity of perceptions (Nader, 1981a). Nader highlighted that the conclusions and decisions of experts often conflict with those reached by the general public, thus enhancing an apparent disconnect between those within and outside specific communities of energy-technology professionals.

Historical examples of energy technology development, such as nuclear energy, have shown that public resistance can have a major influence on the deployment of a technology (Anshelm, 2000; Kasperson et al., 2005; Lovins and Sheikh, 2008; Zimmerman, 1982). The history of nuclear power in the United States also highlights the challenges associated with how the community of professionals associated with a controversial technology is able to integrate public perceptions of risk into their activities and communicate with the public to address opposition (Gamson and Modigliani, 1989; Kasperson et al., 2005; Nader, 1981a; Ohnishi, 1998). More generally, the discrepancy between the perceptions of energy technology experts and those of the general public has been identified and written about (Nader, 1981b). Continued advancement of CCS and the pace at which CCS technology will evolve in the future are therefore dependent on multiple characteristics of the CCS community, including the community's capacity to engage not only with policy makers but also with public concerns and public opposition.

Previous energy technology studies have recognized that experts tend to exhibit overconfidence about and a positive bias towards the particular technology they are working on (Hultman and Koomey, 2007). More generally, it is recognized that positive biases and overconfidence are often perpetuated by communication within groups who tend to focus on factors promoting success (Buehler et al., 2005), whereas pessimistic scenarios are often downplayed (Newby-Clark et al., 2000).

This phenomenon of an apparently shared perspective within a specific community relates to Haas' (1992a) description of the evolution of an epistemic community, or a knowledge-based network of recognized experts who "not only hold in common a set of principled and causal beliefs but also have shared notions of validity and a shared policy enterprise". Understanding the extent to which a given community can be characterized as an epistemic community can provide insights about the effectiveness of its policy intervention, its association with the broader public and the success of communicating the messages that it wants to convey.

The goal of the research presented in this paper is to begin to explore the nature of the CCS community; to provide a preliminary characterization of the community and to consider whether and in what ways the community might be considered to be an epistemic community or, potentially, a compilation of multiple different epistemic communities. To achieve this goal, we first provide background and context on the value of considering community structure and function in relation to the notion of epistemic communities. The national and institutional affiliations of individuals within the international CCS community are then characterized, and content analysis of various CCS community publications is used to assess framing of risks related to CCS within the community. This assessment, although preliminary in scope, provides new perspectives and insights related to the characteristics of the international CCS community, and our final discussion suggests interesting additional areas of related future social science research.

\section{Theoretical background on types of communities}

With the increasing complexity of social and environmental problems that require policy responses, the social dynamics associated with organizing and presenting information to decision makers have become a critical factor in how problems are addressed (Keohane, 1989). Distinct communities of individuals who work collectively to inform decision-makers have emerged in various political arenas at both the international (Adler, 1992; Haas, 1992a, 1992b) and national levels (Adler, 1992; Dotterweich, 2009). At the international level, these communities are often involved in a process involving three steps: (1) framing the range of political controversy surrounding an issue or defining the context, (2) interpreting and defining state interests, and (3) setting standards and developing regulations (Adler and Haas, 1992). Such communities can take different shapes depending on their specific circumstances and the problem to be addressed, and the nature and characteristics of these communities can influence associated policy and technology outcomes.

The theoretical frameworks of these different types of communities include thought collectives (Fleck, 1979), advocacy coalitions (Ellison and Newmark, 2010; Sabatier, 1988; Sabatier and Jenkins-Smith, 1993), and epistemic communities (Antoniades, 2003; Haas, 1992a). Fleck's (1979) framework and concepts on "thought collectives" focus primarily on communities involved in the production of knowledge and facts. An advocacy coalition is a type of community that includes a variety of actors, including journalists, governments, policy analysts and other stakeholders with diverse social interests who are advocating for the same goal (Sabatier and Jenkins-Smith, 1993). According to Haas (1992a), an epistemic community is "a network of professionals with recognized expertise in a particular domain and an authoritative claim to policy relevant knowledge within that domain or issuearea."

Of these frames, epistemic communities offer the most direct and in-depth lens through which to view and examine the nature of the international CCS community. The concept includes two critically relevant components related to the CCS community: experts/professionals and the policy-making context. Sabatier's (1988) concept of advocacy coalitions could also be applied to the international CCS community, but the notion of a CCS advocacy coalition is too broad and inclusive with respect to the professionals who are currently and consistently part of the international CCS dialogue. The international CCS community can be defined in a more limited way with respect to professionals involved in the advancement of this specific technology. Similarly, Fleck's (1979) 


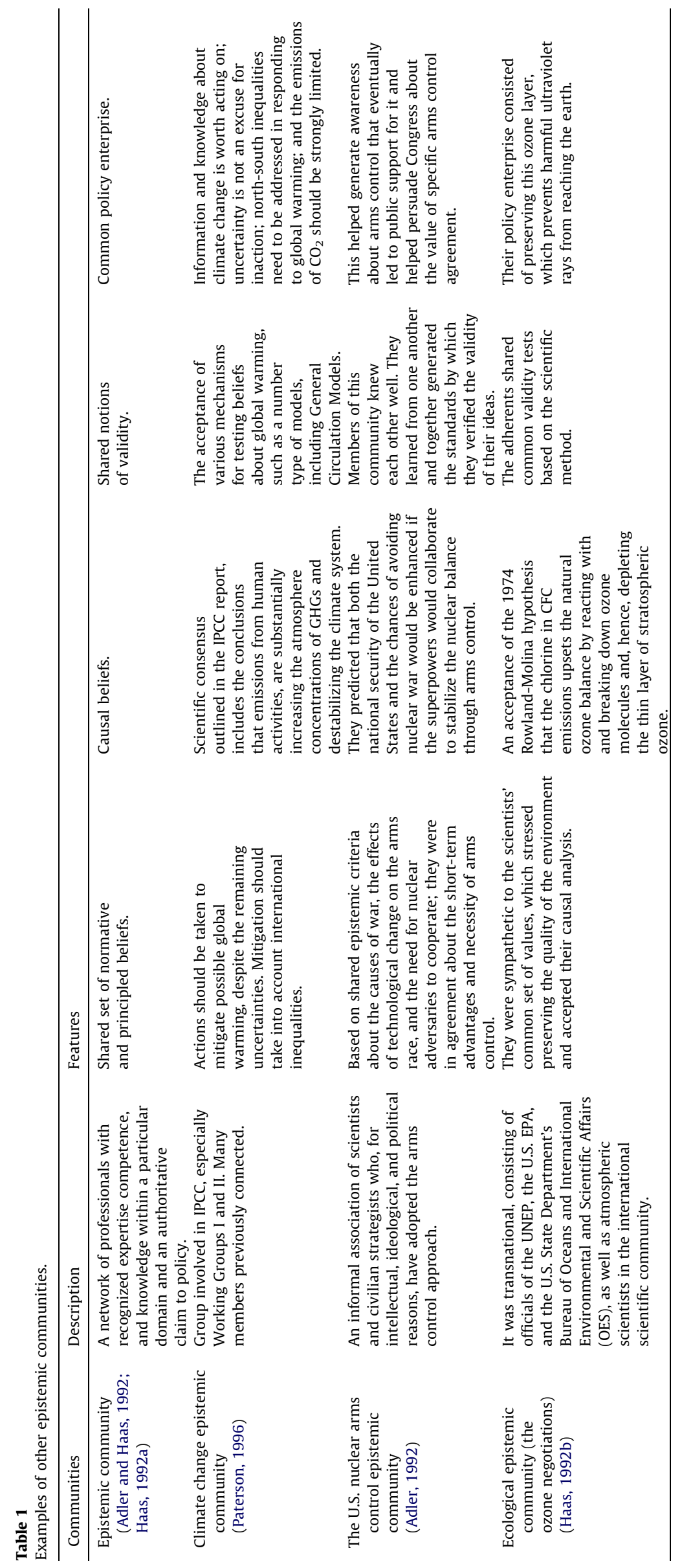


framework is well suited for the analyses of communities of experts, but it does not explicitly integrate the potential policy goals and broader social influences of a community, such as the CCS community.

Haas (1992a) describes epistemic communities as knowledgebased networks of recognized experts who "not only hold in common a set of principled and causal beliefs but also have shared notions of validity and a shared policy enterprise". The four key features of epistemic communities, as described by Haas (1992a), are the following: (1) shared set of normative and principled beliefs, (2) causal beliefs, (3) shared notions of validity, and (4) common policy enterprise. With regard to the common policy enterprise and a community's actual influence on policy, the nature and structure of the community can determine its impact on the policy agenda (Haas, 1992a).

Antoniades expanded Haas' characterization and conceptualized and defined epistemic communities as "thought communities made up of socially recognized knowledge-based networks, the members of which share a common understanding of a particular problem/issue or a common worldview and seek to translate their beliefs into dominant social discourse and social practice" (Antoniades, 2003). The community can focus on two kinds of action: cognitive and practical. The former concentrates on the (re)production of social reality or "truth", i.e., engaging in and promoting a specific perspective. The latter is when group members actively attempt to influence the policy agenda and provide information and/or expertise to policymakers. This can involve multiple kinds of activities, including organizing conferences, seminars, press conferences, public discussions, and lectures and producing publications.

Toke (1999) has criticized Adlers' and Haas' (1992) positivist interpretation and use of the concept of epistemic communities as only emphasizing the community's influence on policy outcomes, hence neglecting other actors (e.g., interest groups and social movements) who might be of importance. These non-epistemic groups may have a significant influence not only on policy processes but also on the participating actors. Furthermore, Toke (1999) criticized Adler and Haas because of their implicit assumption that epistemic communities (experts) are in a better position than, for example, environmental groups, to judge environmental policy because of their knowledge validity and commitment to the "truth".

Farquharson (2003) and Toke (1999) both noted that Haas' interpretation of the concept of epistemic community neglects the relationship between experts and non-experts. The inter-relationship between epistemic communities and the public and the dominant role attributed to experts within the epistemic community seem to be limitations of Haas' framework. The focus remains primarily on interactions between the epistemic community and policy-makers. More recent studies on epistemic communities, however, have explored connections and interactions with the public, though not in relation to environmental issues (Dotterweich, 2009).

A common view within the research field related to epistemic communities is that the aim of an epistemic community is to construct the "truth", or at least knowledge that can be accepted as the truth by policy makers. This "truth" is negotiated within the community. Haas (1992a) claimed that the epistemic community is a central actor in the social construction of knowledge. However, the success of the epistemic community is not only dependent on claims of truth, but also on the existence of successful alliances with decision makers. In this process, there is the potential for an epistemic community's interpretation of facts and knowledge to conform to the community's values, norms and practices (Dotterweich, 2009). This phenomenon could be referred to as an "echo chamber" effect; i.e., the creation of a community within which knowledge and truth claims tend to be re-arranged to fit the preexisting conceptual schemes that already are dominant and accepted by the community. The community's norms and practices both enable and delimit what is feasible and worth striving for (Miller and Fox, 2001).

Previous research on epistemic communities has explored the characteristics of epistemic communities related to several different types of international problems, including climate change (Paterson, 1996), nuclear arms control (Adler, 1992), and ozone depletion (Haas, 1992b). Table 1 summarizes the characterization of these communities with regard to the four key features of different epistemic communities.

\section{Methodology}

This research builds on the theoretical framework of epistemic communities to assess and explore the nature and characteristics of the international CCS community. This initial assessment includes two approaches: a descriptive analysis of the professionals involved in this community (national and sectoral affiliation) and content analysis of various CCS community publications, to assess the framing within the CCS community of the role of CCS in climate change mitigation and of risks associated with CCS.

\subsection{Descriptive analysis of who is involved in the CCS community}

The international CCS community represents a dynamic, evolving network of individuals and organizations who interact professionally across sectoral and national boundaries in the advancement of CCS technology. In an attempt to characterize the current community, we have reviewed the primary sectoral affiliations (business, government, academic, or non-profit, nongovernmental organizations) and the nationality of two sub-sets of individuals with direct involvement in this international network. The first of these sub-sets of individuals includes all authors of peer-reviewed journal articles published in the International Journal of Greenhouse Gas Control Technology from the journal's first issue in 2007 to December, 2010 (968 individuals). This journal was established in recognition of the need within the CCS community for a transdisciplinary publication outlet for the diverse, yet focused research that was being conducted in the field of greenhouse gas control. The second of these sub-sets includes all presenters, co-authors, session chairs and conference committee members at the two most recent International Greenhouse Gas Control Technology Conferences in Washington DC in 2008 and in Amsterdam in 2010. This series of international conferences has been occurring every 2 years since 1992, and the numbers of presenters and participants has increased at each conference. At the 2008 conference, the list of presenting authors, co-authors, session chairs, and conference committee members consisted of 901 individuals, and at the 2010 conference, 1077 individuals were involved.

\subsection{Content analysis of CCS community publications}

A content analysis of three CCS community publications was conducted to characterize how CCS is framed within the international CCS community. The results of this analysis provide information about the framing of CCS in terms of a climate change mitigation option and the framing of risks associated with CCS. In developing the coding protocol, an iterative, repetitive process of testing the intercoder reliability of the researchers doing the analysis was conducted. After the initial codebook was developed, a set of publications was coded by two of the authors who then reconciled their coding to assess intercoder reliability. To minimize 
discrepancies, enhancements were made to the coding protocol before the remainder of the publications were coded.

\subsection{Publications assessed}

Three different publications that reach a diverse portion of the international CCS community were assessed: (1) Greenhouse Issues, (2) The Carbon Capture Journal, and (3) The International Journal of Greenhouse Gas Control Technology. Greenhouse Issues is a newsletter published by the International Energy Agency (IEA) Greenhouse Gas Research and Development (GHG R\&D) program, a combined industry and government implementation agency of the IEA. This newsletter is a publically available online publication that has been published in its current format since September, 2006. The newsletter, which includes approximately 20 articles in each issue and 3-4 issues per year, reports on details of the IEA's GHG program activities and incorporates news from its member countries; it has a readership of over 7000. The Carbon Capture Journal is another newsletter that has a more industry-oriented audience. This newsletter is a publication of the UK-based Carbon Capture Journal Ltd. produced by Digital Energy Journal, one of the world's leading information distribution sources related to information technology and communications in the oil and gas industry. The newsletter, which is publically available online, has been published 6 times a year since 2007 and currently has over 6000 subscribers, is funded by individual and corporate annual subscription fees, corporate sponsorship, and advertisements. The International Journal of Greenhouse Gas Control Technology is a CCS community peer-reviewed journal that began in 2007. This journal is also a publication of the IEAGHG R\&D Program; despite its academic orientation as a peer-reviewed publication, representatives from government and industry also publish papers in this venue.

The two newsletters are available free of charge online to the CCS community and beyond. The intended audience of both of these newsletters is the international CCS community, broadly defined; these newsletters provide project and event updates, and the tone of these newsletters suggests that the editors assume that the audience is already actively engaged or involved with CCS development in some way. The peer-reviewed International Journal of Greenhouse Gas Control Technology requires a subscription or an institutional affiliation for access, and the content is indexed in several international academic databases; the journal has a 5-year impact factor of 3.654 (IJGGC, 2010). The articles in this journal generally contain detailed research results related to multiple components of CCS and other greenhouse gas-reducing technologies.

These particular publications were selected because the collective audiences of these publications span a large and diverse portion of the diversity of professionals within the international CCS community, from industry to academics. Although content analysis of these three publications does not represent a comprehensive review of all publications within the CCS community, these publications represent a cross-section of the written communication within the community.

\subsubsection{Framing of CCS as a climate mitigation option}

The first part of the content analysis assessed how the potential of CCS to contribute to climate change mitigation was framed in each article, in both the newsletters and the journal articles. Every article was categorized into one of four categories: (a) CCS is a necessary technology for climate mitigation; (b) CCS is one of many technologies in the portfolio of options for climate change mitigation, but not essential; (c) no context for the interpretation of CCS's role in climate change mitigation was provided; and (d) CCS should not be considered as a climate mitigation technology. Although the same coding scheme was used for both the newsletters and the peer-reviewed journal articles, for the newsletters, the full article was assessed but for the peer-reviewed articles this characterization was based on reviewing only the abstract, introduction and conclusion because the content of these sections was sufficient to characterize the authors' perspective on the role of CCS. In addition to this framing related to climate change mitigation options, each article was characterized as being either primarily technical (reporting on specific technical details about CCS technology), non-technical (broader non-technical issues,

\section{Table 2}

Characterization of five different types of risks mentioned in the articles. Each category is sub-divided into "risks to" the technology (risks that may slow down the advancement of CCS) and "risks of" the technology (risks that may result if CCS is advanced).

\begin{tabular}{|c|c|c|c|}
\hline Risk coding & Description & Risks to the advancement of CCS & Risk of the advancement of CCS \\
\hline Technical risks (TR) & $\begin{array}{l}\text { Potential problems associated } \\
\text { with technical aspects of CCS } \\
\text { technology. }\end{array}$ & $\begin{array}{l}\text { Complexity of integrating capture, transport } \\
\text { and storage; challenge of characterizing } \\
\text { geological storage potential; selecting } \\
\text { appropriate storage sites. }\end{array}$ & $\mathrm{CO}_{2}$ leakage. \\
\hline Political risks (PR) & $\begin{array}{l}\text { Problems associated with the } \\
\text { politics or policy of CCS } \\
\text { technology. }\end{array}$ & $\begin{array}{l}\text { Uncertainty of climate change policy; lack of } \\
\text { government support; lack of regulation for } \\
\text { CCS, including addressing storage site } \\
\text { long-term liability and jurisdiction. }\end{array}$ & $\begin{array}{l}\text { Detract from political support for } \\
\text { renewable energy; could } \\
\text { perpetuate dependence of fossil } \\
\text { fuel; etc. }\end{array}$ \\
\hline Economic risks (ER) & $\begin{array}{l}\text { Problems associated with the } \\
\text { cost of CCS technology. }\end{array}$ & $\begin{array}{l}\text { High cost of building full-scale plants; energy } \\
\text { penalty associated with } \mathrm{CO}_{2} \text { capture; } \\
\text { insufficient investment; uncertainty of } \\
\text { economic payback and government subsidies. }\end{array}$ & $\begin{array}{l}\text { Rising electricity prices for } \\
\text { consumers; changing prices of } \\
\text { emissions rights; reduction of } \\
\text { financial investment in } \\
\text { renewable technologies. }\end{array}$ \\
\hline Social risks (SR) & $\begin{array}{l}\text { Problems associated with public } \\
\text { perception and social concerns of } \\
\text { CCS technology. }\end{array}$ & $\begin{array}{l}\text { Lack of public understanding and acceptance } \\
\text { of CCS technology; community opposition; } \\
\text { media and NGO criticism. Public concerns and } \\
\text { worries about the safety of CCS technology. }\end{array}$ & $\begin{array}{l}\text { Lack of public understanding and } \\
\text { acceptance of CCS technology; } \\
\text { community opposition; media } \\
\text { and NGO criticism. Public } \\
\text { concerns and worries about the } \\
\text { safety of CCS technology. }\end{array}$ \\
\hline $\begin{array}{l}\text { Environmental } \\
\text { risks (EnvR) }\end{array}$ & $\begin{array}{l}\text { Problems associated with the } \\
\text { environment impacts of CCS } \\
\text { technology. }\end{array}$ & $\begin{array}{l}\text { The adverse impacts on ecosystem and human } \\
\text { health resulting from } \mathrm{CO}_{2} \text { leakage. Ground } \\
\text { water contamination; ground upheaval; } \\
\text { abrupt large-scale leakage; biodiversity } \\
\text { impacts. }\end{array}$ & $\begin{array}{l}\text { The adverse impacts on } \\
\text { ecosystem and human health } \\
\text { resulting from } \mathrm{CO}_{2} \text { leakage. } \\
\text { Ground water contamination; } \\
\text { ground } \\
\text { upheaval; abrupt large-scale } \\
\text { leakage; biodiversity impacts. }\end{array}$ \\
\hline
\end{tabular}


including legal, regulatory, or public perception issues), or not at all about CCS.

\subsubsection{Framing of risks: "risks to" CCS and "risks of" CCS}

An additional part of the content analysis involved coding for the extent and types of CCS risks and the perspectives related to them that were mentioned in the two newsletter-type publications. For this qualitative coding, risks are considered to be any obstacles, barriers, problems, or challenges related to the technology, or any negative impacts or implications of the technology. An initial step characterized all risks of CCS as fitting into one of five general types of risks: technical, political, economic, social or environmental (Table 2). These categories of risk were adapted from the SPEED (Socio-Political Evaluation of Energy Deployment) framework developed to assess the complexity of factors influencing deployment of emerging energy technologies (Stephens et al., 2008). Additionally, all risks were characterized as either being framed as "risks to" the technology or "risks of" the technology (Table 2). A "risks to" the technology refers to risks that are explicitly related to CCS progress; i.e., barriers or obstacles to the timely, sound and efficient development of CCS. "Risks of" the technology refer to risks that CCS may represent for society or energy systems; hence, the latter risks are neither primarily framed as limiting the progress of CCS nor evaluated in relation to their influence on CCS (e.g., the risk that the deployment of CCS delays the development of renewable energy sources). Within the social and environmental risk categorization in Table 2, the "risks to" and "risks of" are described as being the same; however, it should be noted that the interpretation of the consequences of the risks may differ depending on the reader's perspective.

\section{Results}

\subsection{Characterization of the international CCS community}

The characterization of the sectoral and national distribution of the international CCS community, as represented by those authors contributing to The International Journal on Greenhouse Gas Control Technology from 2007 through 2010 (Figs. 1a and 2a) and those attending the 2008 and 2010 International Greenhouse Gas Technology conferences (Figs. 1b, c and 2b, c) shows a distinct sectoral diversity and national distribution. Of the 968 authors who contributed to the peer-reviewed journal (authors who published more than one article were only counted once), approximately 50\% are academics, $30 \%$ are government affiliated, $20 \%$ are associated with business, and $2 \%$ are NGO representatives (Fig. 1a). When this distribution of authors is compared to the sectoral distribution of individuals who were presenting, coauthoring a paper being presented, or organizing a session at the GHGT-9 conference (Fig. 1b) and the most recent GHGT-10 conference (Fig. 1c), the conferences were characterized by a higher percentage of business representatives, a lower percentage of academics, and approximately the same percentage of government affiliates and NGO representatives. This sectoral difference between those publishing in the peer-reviewed journal versus those presenting or organizing at the international conference is not surprising given that among these sectoral groups, academics have the most explicit incentive and motivation to publish in a peer-reviewed journal, whereas attending and presenting at a conference would be expected to be more highly valued by business representatives than publishing in a peer-reviewed journal. Additionally, academic professionals' participation in these international conferences could also be restricted due to more limited travel budgets compared to business representatives. The overall distribution represented in Fig. 1 demonstrates the diversity of individuals and types of organizations that make up the international CCS community, highlights the fact that the community is not dominated by one sector, and suggests that there is regular interaction at conferences among individuals representing these various sectors.

The national affiliations of these sub-sets of individuals provide additional information about the character of the international CCS community (Fig. 2). Among those publishing in the peer-reviewed journal (Fig. 2a), the countries with the most contributing authors are closely matched with those countries that have invested the most in CCS (Meadowcroft and Langhelle, 2009; Tjernshaugen, 2008; van Alphen et al., 2010). The United States clearly dominates, followed by Norway, Japan and the Netherlands. The national affiliations of those involved in the GHGT-9 conference and the most recent GHGT-10 conference (Fig. 2b and c) do not demonstrate the same distribution as that of the authors contributing to the journal, though the USA also dominates in this case. With regard to the GHGT-9 conference, the US was the host country, so part of the disproportionate US representation engaged in the conference can be attributed to the ease of attending a conference in one's home country. The GHGT-10 conference also exhibited the largest number of representatives coming from the US, but the proportions of attendants from European countries increased compared to GHGT-9, which was likely due, at least in part, to the GHGT-10 meeting being located in the Netherlands. Fig. 2 provides additional support for the idea that the countries investing the most in CCS are those that are most engaged in the international CCS community.
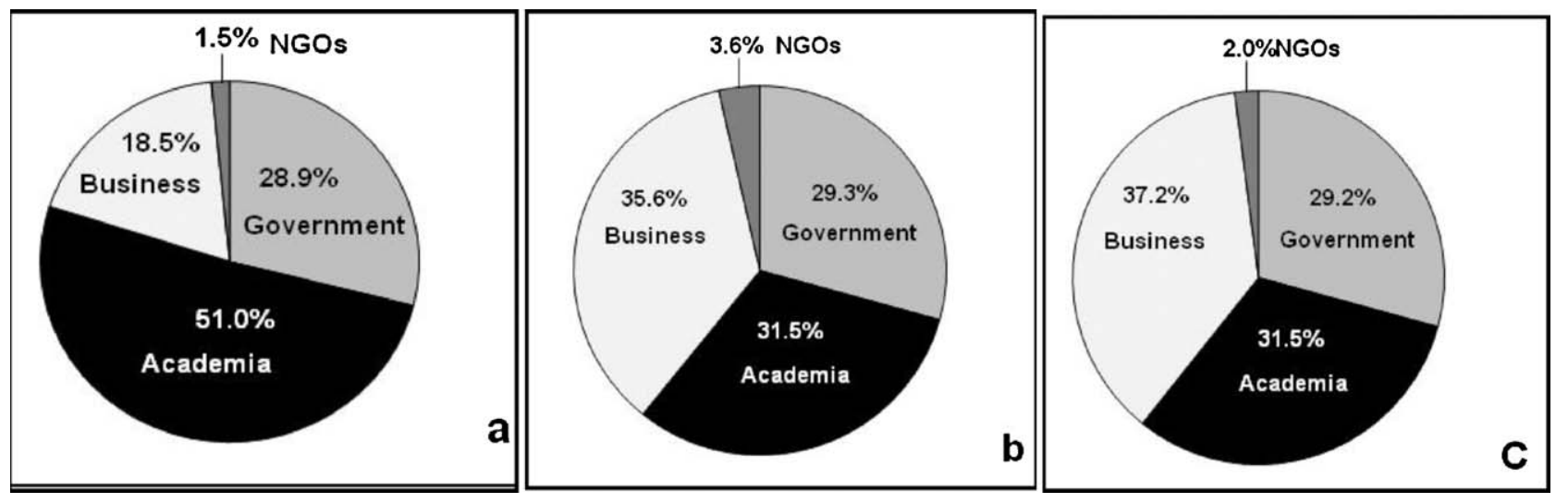

Fig. 1. The sectoral distribution of (a) authors who have contributed to the International Journal on Greenhouse Gas Control Technology from 2007 to 2010 and (b) individuals who were actively engaged in the International GHGT-9 conference in Washington DC in November 2008, and (c) individuals who were actively engaged in the GHGT-10 conference in Amsterdam, the Netherlands in September 2010. 

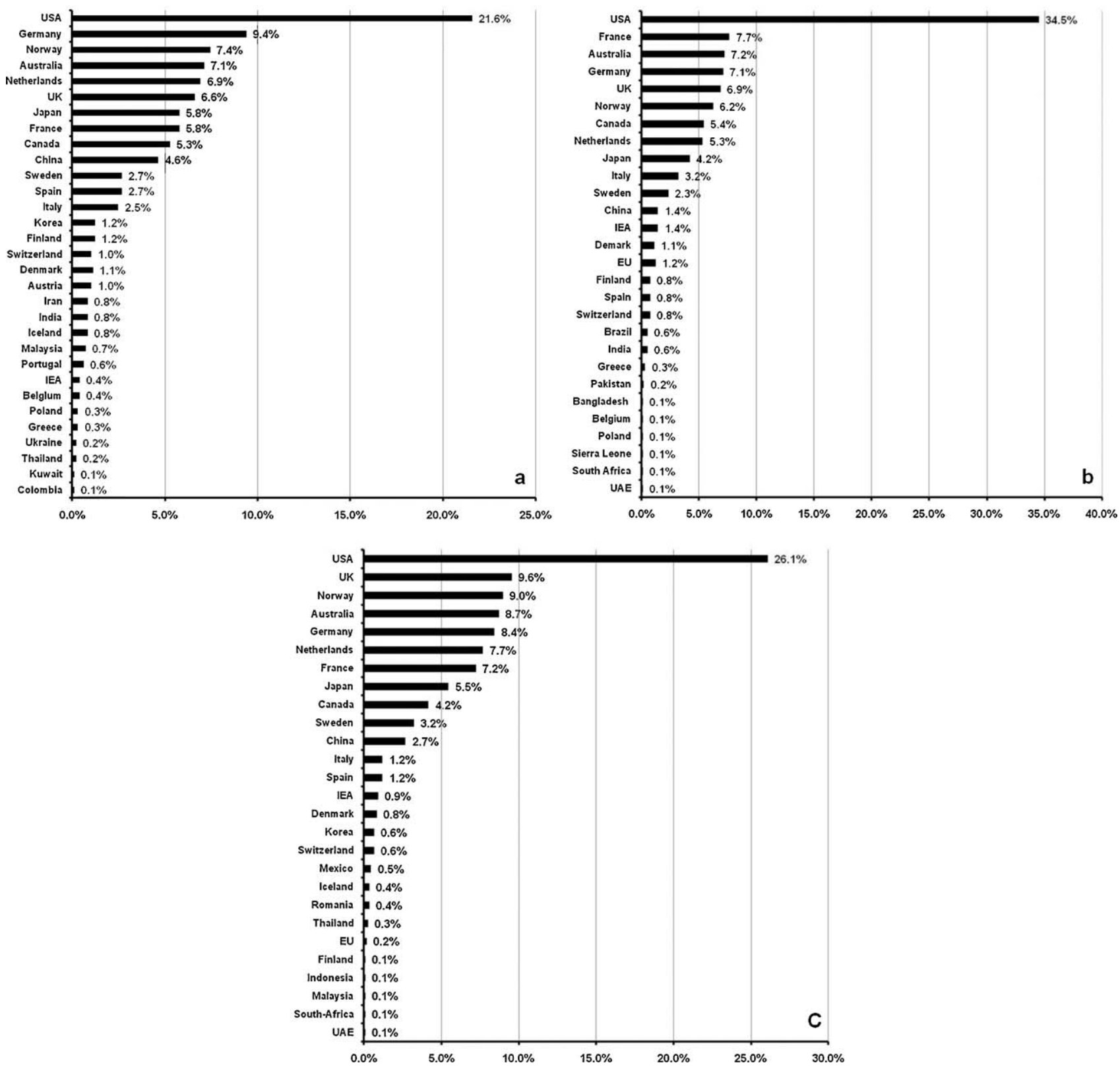

Fig. 2. The national affiliation of (a) authors who have contributed to the International Journal on Greenhouse Gas Control Technology from 2007 to 2010 , and (b) individuals who were actively engaged in the International GHGT-9 conference in Washington DC in November 2008, and (c) individuals who were actively engaged in the GHGT-10 conference in Amsterdam, the Netherlands in September 2010.

\subsection{Content analysis}

\subsubsection{Framing of CCS in climate mitigation}

The results of our analysis assessing the framing of CCS related to its potential to contribute to climate change mitigation in both the newsletters (Fig. 3a) and the peer-reviewed articles (Fig. 3b) demonstrate a positive perspective on the role of this technology. In both types of publications, some articles explicitly characterized CCS as a necessary technology for climate mitigation (almost $11 \%$ of the newsletter articles and over $8 \%$ of articles in the peerreviewed journal). More than half of the newsletter articles did not mention a context for the role of CCS in climate mitigation (these articles included event announcements, job descriptions, and other materials that would not include a characterization of the role of CCS in climate mitigation). For the peer-reviewed journal articles, $42 \%$ of the total articles mentioned the role of CCS as one of many technologies in the portfolio of options for climate change mitigation. No articles in either the newsletters or the peerreviewed journal characterized CCS as a technology that should not be considered as a climate mitigation option, revealing an optimistic and non-critical perspective within the international CCS community with regard to the role of CCS technology in climate mitigation.

An analysis of the peer-reviewed articles published in the Journal of International Greenhouse Gas Control Technology showed that approximately $72 \%$ of the articles were purely technical, focusing on technical details of CCS engineering; $18 \%$ were non-technical, focusing on legal, regulatory or public perception issues associated with CCS; and approximately $10 \%$ of the articles were not at all about CCS, but were about other greenhouse gas control technologies (Fig. 4). The fact that only $10 \%$ of the articles published in this journal are not about CCS is a confirming indicator that this publication is a critical CCS community publication. 

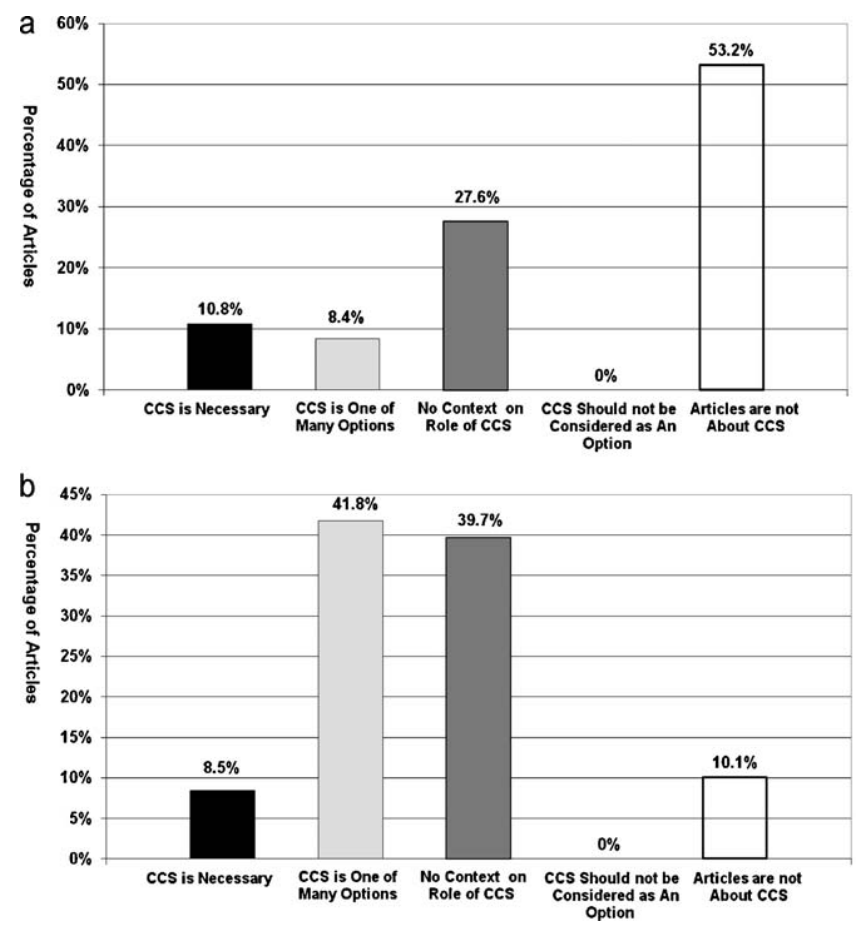

Fig. 3. The comparison of the role of CCS in climate mitigation between newsletters and journals, and (a) the percentages of articles of five codings in newsletters 20072009 , and (b) the percentages of articles of five codings in journals 2007-2009.

\subsubsection{Framing of CCS risks}

Fig. 5 represents the distribution of the different types of risks mentioned or discussed in the newsletter-type publications from September, 2006 to December, 2009. Technical risks dominate, as they are mentioned most frequently. Political risks are the next most frequently mentioned type of risk, followed by economic risks. Environmental and social risks are mentioned the least often.

Additional qualitative analysis to further understand the risks discussed in these newsletters involved categorizing the risks as either "risks of" CCS or "risks to" CCS (Table 2). Even though risks of various kinds are acknowledged, or even addressed in specific research projects the vast majority of the articles in the newsletters are characterized by a sense of optimism. The typical framing of CCS consists of briefly mentioning a number of risks to the development of CCS. However, the risks are, in most cases, described as being very likely to be manageable, at least if CCS obtains sufficient governmental support and public acceptance, i.e., the strictly techno-scientific risks will be solved if enough resources and support are received. Within many of the articles in

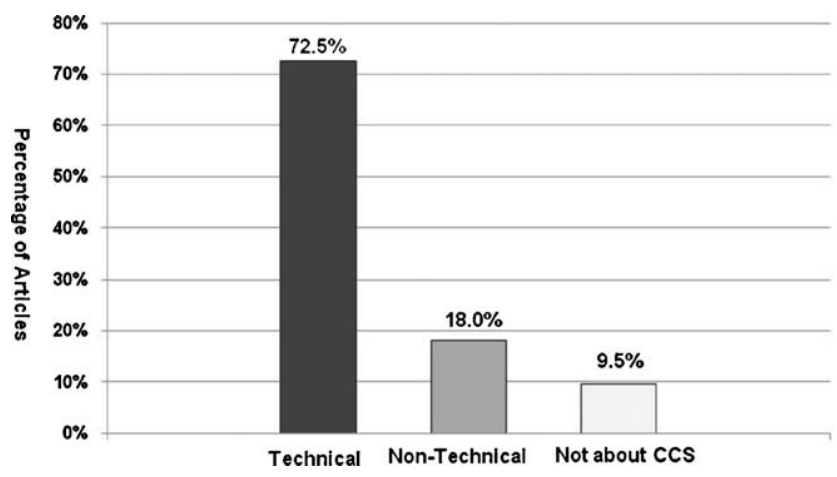

Fig. 4. The percentages of peer-reviewed articles published in the International Journal of Greenhouse Gas Control Technology that were technical, non-technical or not about CCS in the years 2007-2009.

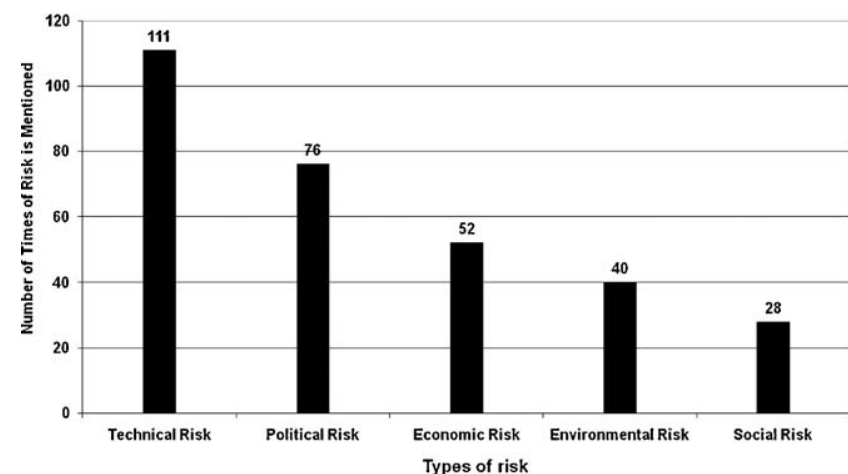

Fig. 5. Distribution of the number of different types of risks mentioned or discussed in the newsletter-type publications from September 2006 to December 2009.

the newsletters, risks are framed most often as "risks to" the development of CCS. Significantly fewer of the articles frame "risks of" CCS, including mentioning potential negative impacts that the advancement of CCS may have on development of other energy technologies, on public safety, and on fossil-fuel dependence.

A significant share of the articles deal with risks associated with transport, injection and storage safety and liability issues. Those articles are, in most cases, framed clearly as "risks to" the development of CCS and not as "risks of" CCS, because the risks are primarily framed as impeding the development of CCS. In some cases, it is difficult to dichotomize "risks to" and "risks of" CCS development. Several articles describing storage projects aimed at evaluating potential impacts on health, safety and the environment were included in this review. These articles describe both risks to and risks of CCS. However, the consequences of leakages, for example, are in most cases framed first as something that might stop the development of CCS and are not framed as the environmental impacts thereof. This perspective, which we labeled as a causal belief, seems logical because the aim of the newsletters is to provide information regarding CCS-related progress and activities, and the mission of most members of the CCS community is to work towards implementation of the technology. Furthermore, this framing seems to be consistent with the perspectives represented in Fig. 3a, i.e., about $10 \%$ of the newsletter articles describe CCS as a necessity for climate change mitigation. This view leaves little room for considering not developing CCS. Hence, the risks of CCS are justified and are first valued in relation to whether they pose a risk to CCS or not. Therefore, in a context where the decision seems to have already been made that a particular technology should be developed, a common goal seems to be accelerating its development as efficiently as possible while simultaneously trying to minimize potential risks of the technology.

Articles discussing or mentioning the climate change consequences of not developing CCS (risks to) outnumbered articles on the consequences of developing CCS (risks of), which seems to represent yet another of the causal beliefs within the community. This quote from the Norwegian NGO Bellona illustrates the former perspective: "We should engage in a dialogue to provide information and awareness and promote enthusiasm for this very important technology without which we will not reach our goal to stay below two degrees temperature change" (CCJ, issue 8, p. 6).

A minority of articles did express critical concerns regarding CCS, its specific components or its appropriateness in specific geographical areas. For example, some geologists are not convinced about supporting a specific storage project because it may leak (GI, issue 85). Leakage is also discussed from an insurance perspective in another article. This article concludes that no matter the size of the insurance, it will not cover major leakages. 
Consequently, risk management tools are assumed to only be able to manage "low frequency potentially catastrophic losses" (GI, issue 93, p. 7). Accordingly, there will always be a risk of CCS related to geological storage, even though this is not a main issue addressed in many articles. In this context, it is notable that one article raises the issue that the data related to storage probably is overly optimistic and is based on estimations that are too general (CCJ, issue 7, p. 13). This optimism is represented by the following quote from another article: "CCS safety risks are manageable. Based on 5 years research it provides evidence that geological storage works at scale now and is safe, permanent and costeffective" (CCJ, issue 11, 26).

As mentioned above, a widespread perspective is that the multiple risks of CCS are manageable. The following discussion represents some of the community's shared notions of validity, which are characterized by a strong belief in engineering knowledge. This perspective can be illustrated by this quote from a leader article: "The risks will be regulated properly. We can manage the technical challenges, but do not know how to deal with the public acceptance" (CCJ, issue 8, p. 4). In addition to statements like this, it is sometimes mentioned that the promotion of CCS could be enhanced with the help of environmental NGOs, given that they generally have a better reputation among laymen than the fossil fuel industry. However, a number of obstacles are also highlighted in these reports. Under the heading "Winning the PR battle of CCS" it is said that the industry should "convince hard line activists that it is safe and will not cause undesirable side effects" (CCJ, issue 4, p. 8). The article continues by interconnecting technical issues and acceptance. A common standpoint is that once the technical issues are addressed and overcome there will be "legitimate questions of health and safety raised by environmental and grassroots citizen activist groups, which could be blown up considerably by the media. The debate over the viability of CCS cannot be confined to the elites of academia, engineering, industry and government $/ .$. /this is a battle for the hearts and minds of society at large" (CCJ, issue 4, p. 8 ).

Despite the prevalent technically optimistic tone in these articles, a few critical statements are included in approximately one article per newsletter issue. Two of the critical articles paraphrase the statements of environmental NGOs. For example, the WWF is reported as stating that: "Rapid deployment of demonstration plants is necessary to determine whether CCS is practical for broad application, and if it doesn't work we need to know even sooner" (CCJ, issue 3, p. 15). Furthermore, Greenpeace's attendance at an IEA GHG meeting in the Netherlands was reported in one article in which it was mentioned that this environmental NGO was reluctant to support CCS given its links to fossil fuels and the belief that CCS will negatively influence the development of renewables (GI, issue 86 ). The latter concern is expressed very seldom in the articles in these newsletters; in contrast, it is a major concern among MP's in the European Parliament and in the mass media according to a survey (based on a relatively small sample) conducted by Shackley et al. (2007). Some parliamentarians in Europe appear to have adopted a somewhat critical view of CCS, and academia does not appear to be adopting a critical response but, rather, one that is more typical of the responses of energy industry (Shackley et al., 2007).

Furthermore, a couple of authors comment on what they assume to be the considerable risk of granting permits to power plants today and the consequence that CCS retrofitting of plants will be delayed or shelved later on (GI, issue 91). Another perspective that is presented is to emphasize the risk of not building capture-ready power plants (CCJ, issue 4, p. 10). However, another article expresses similar concerns, as its authors quote a survey study claiming that only $34 \%$ of their 1000 respondents were confident that clean coal technology and CCS retrofitting will

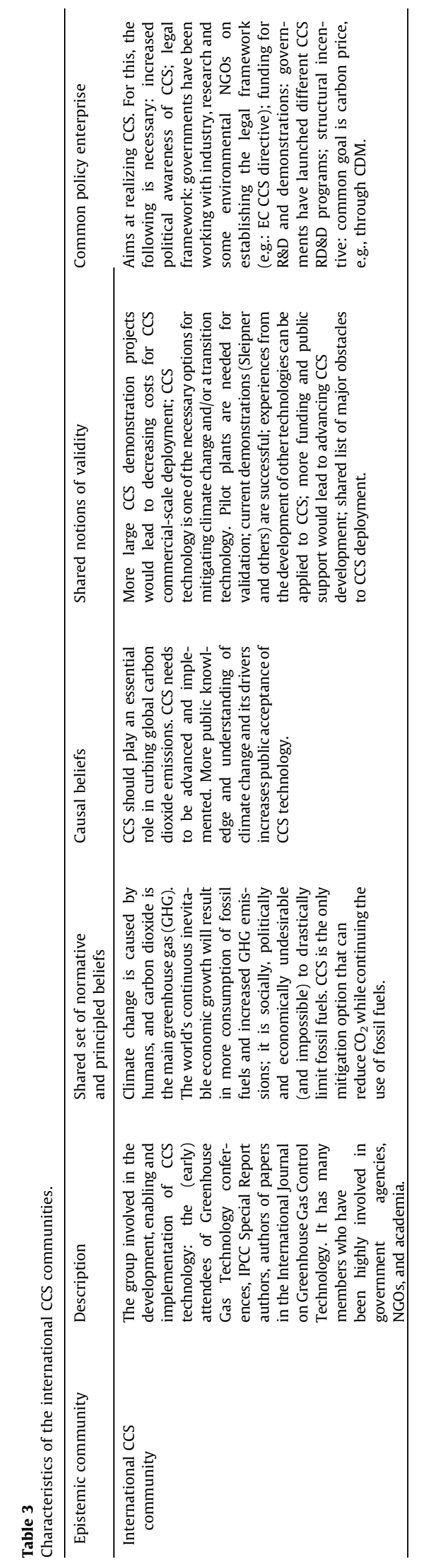


mitigate emissions in the next 23 years at reasonable costs, and $36 \%$ believed that implementing CCS in new power plants would have a timely positive effect, which is considerably lower than the optimism regarding renewables (CCJ, issue 1, p. 14). A few authors express concerns that CCS in CDM might have negative effects on the global carbon market due to an increased supply of carbon credits. However, they conclude that CCS in CDM may not have significant ramifications for the global carbon market or other CDM technologies (GI, issue 93, p. 13).

\section{Epistemic community characteristics within the international CCS community}

The international CCS community is a diverse international community that has been rapidly growing for the past 5 years. The sectoral diversity among governments, business, academia and some NGOs is strong, as is diversity in national representation (Figs. 1 and 2). Although this diversity results in complexity in the community which may detract from the characteristics of epistemic communities, this diversity creates a stronger need for the community to unify.

Despite the diversity within the community, the framing of CCS in climate mitigation shows a shared notion of validity. None of the articles about CCS frame it as a technology that should not be considered as a climate mitigation option, and the framing of risks tends to focus on risks that may prevent or slow down the advancement of the technology, rather than risks associated with the advancement of the technology. This risk framing supports and reinforces the assessment that the international CCS community has a shared notion of validity and principled and causal beliefs.

The degree to which individuals within the CCS community actively support or advocate for CCS advancement varies greatly based on our analysis of newsletters, ranging from pragmatism to high levels of support; only a few actually mention opposition to supporting CCS advancement. The community does exhibit an overall sense of promoting the technology to enhance society's capacity to respond to climate change. Acknowledging this generalization, we also recognize the distinct heterogeneity of the CCS community and the prevalence of individuals and organizations within the CCS community who are skeptical of the utility of advancing the technology (Baker et al., 2009). For example, Greenpeace International is an organization that has been an active member of the international CCS community in multiple ways, including participating in CCS workshops and meetings and having representatives serving as authors on the Intergovernmental Panel on Climate Change (IPCC) Special Report on CCS (IPCC, 2005). At the same time, Greenpeace has been among the most influential and outspoken critics of CCS (Greenpeace International, 2008).

A summary of the most important characteristics of the CCS community that relate to Haas' definition of an epistemic community is presented in Table 3. Within the CCS community, shared causal beliefs include the view that CCS is technologically feasible and can contribute to large-scale reductions in $\mathrm{CO}_{2}$ emissions from industrial sources to mitigate climate change. Shared notions of validity have been derived from debating and finding solutions to the five different types of risks associated with CCS (Table 2). The results of the analysis assessing the community's framing of the role of CCS in climate change mitigation indicate that a positive perspective on the potential climate change mitigation contribution of CCS technology is dominant. Based on their common beliefs, the international CCS community has been influencing national and transnational CCS policy (Table 3). Although it is large, diverse and international, the CCS community clearly displays some characteristics of an epistemic community, as it operates based on a consensual knowledge base, shared notions of validity and a common policy enterprise.

\section{Discussion and conclusions}

Sections 4 and 5 provided a preliminary characterization of the international CCS community, suggesting that the community has some characteristics of an epistemic community. In this section, we expand on this previous description, making connections to theoretical analyses and considering possible implications. Finally, we make some suggestions for further research.

This preliminary characterization of the CCS community suggests that the international CCS community could be considered to be a rather large epistemic community, but it could also be considered as a compilation of multiple smaller epistemic communities, each with more specific national or sectoral foci. Arguably, the CCS community is somewhat different and more diverse and complex than similar networks that have developed around other more established technologies. We suggest this because CCS is not a single new technology but a complex set of technological components, many of which have been commercially deployed in a variety of industrial applications for many years. CCS technology, therefore, depends on experts from a wider range of disciplines than many other emerging technologies; i.e., electrical engineers, chemists, engineers, geologists, sociologists, pipe-line experts, the oil-industry, coal industry, mining industry and "water experts" have all been involved in the development of CCS technology, but only for a relatively short period of time. This diversity is apparent in previous research that has highlighted institutional fragmentation and a lack of sound international communication and coordination among CCS demonstration projects (Coninck et al., 2009).

Regardless of the community's heterogeneity, a shared perception of the value of advancing CCS technology is generally assumed among those within the community. The diversity of professionals focused on the advancement of one specific technology system can be considered related to the technological complexity of CCS but can also be related to the high degree of uncertainty associated with the potential integration of CCS into existing energy infrastructure systems and scaling up. Haas (1992a) suggests that uncertainty is one factor that creates a circumstance for a network of experts to assemble and converge, and high uncertainty with regard to CCS is a probable convening influence.

The community seems to have a consistent and rather homogenous policy message related to the need for government support to advance the technology. In some contexts, the community demonstrates effective coherent communication about this policy message, which is reflected in some of the literature analysis presented here. Consistent communication has resulted in specific policy implications; for example in the EU, the CCS community successfully lobbied for billions of Euros in demonstration funding to be allocated to the Zero Emissions Platform (ZEP). The Carbon Sequestration Leadership Forum, a ministerial-level organization focusing on the international development of CCS, also represents an important sub-group within the larger epistemic community that has both resulted from and itself promoted an increased level of government support for CCS technology advancement.

Our text analysis revealed a limited degree of negative critique taking place within the international CCS community, though there are some distinct and consistent mentions of risks. The community is clearly aware of and acknowledging, discussing, and trying to address risks. A critically important point, however, that this analysis demonstrates is that within the epistemic community, risks are framed primarily as "risks to" the technology rather 
than "risks of". The issue of whether or not CCS should be developed is not the major subject for discussion within the community, and "risks of" the technology are seldom explicitly addressed. Similar to what (Lounsbury and Glynn, 2001) and Haas (1992a, 1992b) pointed out as being general attributes among developers of technologies or epistemic communities, the CCS community seems to promote narratives about what CCS is, how it will contribute to society and what the major risks to the technology are. The CCS community is a growing, diverse, global network of professionals that is embedded within and inextricably linked to the larger community committed to climate change mitigation. Many community members' views of CCS technology are fundamentally based on shared beliefs and notions of validity, or at least shared rhetoric, about three things: (1) climate change is a serious threat based on human-induced greenhouse gas emissions; (2) the continued use of coal in the electric power sector is inevitable; and (3) a strong conviction that CCS demonstration will advance the technology.

Technological advocacy is a necessary part of the innovation process (Hansson and Bryngelsson, 2009; Hekkert et al., 2007), and technological advocacy is the fundamental mission of several of the organizations within the international CCS community (CSLF, 2010; Global CCS Institute, 2009). The international CCS community seems generally to have organizational affiliations that promote CCS and have a positive bias towards CCS because of personal efforts to develop CCS (Shackley et al., 2007).

One recognized challenge associated with epistemic communities in practice is that the focus on influencing policy at a macrolevel can result in a disconnect with general public concerns (Dotterweich, 2009). Within the international CCS community, there are multiple signals suggesting that there this is a disconnect with public concerns (social risks) and negative critique; this disconnect has also been principally neglected in Haas' (1992a) and Haas' (1992b) research on epistemic communities. Exploring and characterizing this disconnect and differences in risk perceptions, discourse, and priorities represent valuable areas of future research. As public participation and acceptance are an increasingly important component of environmental decision-making, broadly, and technology deployment, more specifically (Beierle and Cayford, 2002), more attention and research into this disconnect is warranted.

While the framing of risks within the international CCS community emphasizes "risks to" the advancement of CCS more than "risks of" the technology, public concerns about CCS tend to focus more on "risks of" the advancement of the technology. Both types of public concerns, i.e., global concerns associated with the technology as a resource-intensive, fossil-fuel-promoting, renewable energy source-competing, technologically complex climate mitigation option and more local project-specific concerns among communities that are confronted with proposed projects can be categorized as predominantly "risks of" the technology. To offer further insight into why the risks mentioned within the CCS community tend to focus on "risks to" the technology; although outside the CCS community, the risks tend to focus on "risks of" the technology, it is worth considering a fundamentally different set of assumptions that influences the discourse within the community versus that outside the community.

Although the present study is unable to confirm or deny whether or not a bias of over-optimism exists within the CCS community, previous research has empirically exemplified what the results of technology over-optimism or of prohibitive discourses might be (Malone et al., 2009; Stephens and Jiusto, 2010). A strong advocacy perspective may detract from the community's collective capacity to critically evaluate the risks and potential negative implications of specific policies or decisions associated with advancing the technology and may also reduce the community's effectiveness in responding to skeptical or critical perspectives about CCS from outside the community (Coninck, 2010; Malone et al., 2009). Furthermore, over-optimism may result in disappointment if expectations are not fulfilled or subsequent inappropriate regulatory adjustments, amendments, or sub-optimal investments are made (Anshelm, 2000; Smil, 2000).

Strong internal advocacy within an epistemic community has the potential to lead to divergence rather than convergence in visions of the technology between the general public and the community. As mentioned previously, epistemic communities tend to re-arrange truth claims to fit pre-existing conceptualizations that already are dominant within the community (Dotterweich, 2009). Hence, engaging in negative critiques or obtaining external perspectives becomes important because the public clearly has concerns about the technology that may not be aligning with those of CCS community. To gain or maintain trust, the CCS community needs to be sensitive to a wide range of concerns outside of the epistemic community. The importance of this sensitivity to concerns outside of the community can be illustrated by previous negotiations regarding the role of CCS in the Kyoto Protocol's Clean Development Mechanism (CDM) (Coninck, 2008). The international CCS community, which was strongly in favor of integrating CCS into the CDM, focused on a few surmountable and procedural barriers, whereas external communities that were opposed to this integration emphasized a range of convictions that we consider being closely related to "risks of" CCS (e.g., sustainable development aspects and whether developing countries would benefit or be worse off).

We recognize that the international CCS community is a heterogeneous and dynamic community, so many individuals within the community are at different stages of development of their ideas, and a broad spectrum of perspectives, disciplines, and nationalities is represented. Nevertheless this analysis has begun to explore and demonstrate some characteristics and trends associated with this dynamic community, and this initial attempt at characterizing the community suggests several areas of future social research on CCS and other climate mitigating technologies. A more in-depth comparison of the social networks associated with various different critical climate-mitigating energy technologies would be helpful to determine similarities and differences between CCS, a fossil-fuel technology, and other technologies, including renewables and nuclear energy.

Additionally, an investigation of the relationship between and a comparative analysis of the discourse within the CCS community and the general public would be valuable and could reveal insights relevant to the advancement of various different types of technologies with high perceived risks that are susceptible to public opposition. An improved understanding of whether and to what extent perspectives within the CCS community incorporate and address broader public concerns about the technology would be valuable. Additional interesting and valuable work could explore the hypothesis that the international CCS community is composed of professionals that share increasingly self-reinforcing views on the technology, its importance, and its risks.

An additional suggested area of social science research involves documenting and assessing how the CCS epistemic community has influenced policy-makers. Exploring how policymakers perceive, accept and understand the knowledge and perspectives that are communicated to them from the epistemic community could reveal insights about policy-makers' capacity to critically assess experts opinions.

In conclusion, this characterization suggests that although the CCS community may be influencing decision-makers and successfully garnering political support for advancing CCS technology, the potential disconnect with the concerns of a broader public is deserving of more attention and social science research. 


\section{Acknowledgements}

The authors thank the Swedish MISTRA Foundation for Strategic Environmental Research for supporting this international collaborative project and to the editors of this special addition, Karin Bäckstrand, James Meadowcroft, and Michael Oppenheimer for their feedback and suggestions that have greatly improved the quality of this paper. The valuable comments and suggestions of two anonymous reviewers are also greatly appreciated. Appreciation is also given to the other researchers involved in this MISTRA CCS project who through several workshops have also contributed to the development of this work. Anders Hansson also acknowledges funding from Mistra Clipore.

\section{References}

ACCSEPT, 2007. The ACCSEPT Project: Summary of the Main Findings and Key Recommendations.

Adler, E., 1992. The emergence of cooperation: national epistemic communities and the international evolution of the idea of nuclear arms control. International Organization 46 (1), 101-145.

Adler, E., Haas, P.M., 1992. Conclusion: epistemic communities, world order, and the creation of a reflective research program. International Organization 46 (1), 367-390.

Anshelm, J., 2000. Between Salvation and Judgement Day - On the Nuclear Power's History of Ideas in Sweden 1945-1999 (our translation). In Swedish. Mellan frälsning och domedag - om kärnkraftens politiska idéhistoria i Sverige 19451999. Symposium, Eslöv.

Antoniades, A., 2003. Epistemic communities, epistemes and the construction of world politics. Global Society 17 (1), 21-38.

Baker, E., Chon, H., Keisler, J., 2009. Carbon capture and storage: combining economic analysis with expert elicitations to inform climate policy. Climati Change 96, 379-408.

Beierle, T.C., Cayford, J., 2002. Democracy in Practice: Public Participation in Environmental Decisions. RFF Press, Washington, DC.

Bielicki, J., Stephens, J.C., 2008. Public Perception of Carbon Capture and Storage Technology Workshop Report. Harvard Kennedy School, Cambridge, MA

Buehler, R., Messervey, D., Griffin, D., 2005. Collaborative planning and prediction: Does group discussion affect optimistic biases in time estimation? Organizational Behavior and Human Decision Processes 97, 47-63.

Climate Group, Ecofin, GCCSI, 2010. Carbon Capture and Storage: Mobilising Private Sector Finance. http://new.globalccsinstitute.com/sites/default/files/CCS Mobilising-Private-Sector-Finance-Report-20Sep2010_1_1.pdf.

Coninck, H.d., 2008. Trojan horse or horn of plenty? Reflections on allowing CCS in the CDM. Energy Policy 36 (3), 929-936.

Coninck, H.d., 2010. Advocacy for carbon capture and storage could arouse distrust. Nature 463 (7279), 293-1293.

Coninck, H.d., Stephens, J.C., Metz, B., 2009. Global learning on carbon capture and storage: a call for strong international cooperation on CCS demonstration. Energy Policy 37 (6), 2161-2165.

CSLF, 2010. Carbon Sequestration Leadership Forum, Technology Roadmap: A Global Response to the Challenge of Climate Change. http://www. cslforum.org/publications/documents/CSLF_Technology_Roadmap_2010.pdf.

Dotterweich, L.J., 2009. Who knows what? A study of the role of epistemic communities in the making of the no child left behind act. Kent State University.

Ellison, B.A., Newmark, A.J., 2010. Building the reservoir to nowhere: the role of agencies in advocacy coalitions. Policy Studies Journal 38 (4), 653-678.

Feenstra, C.F.J., Mikunda, T., Brunsting, S., 2010. What happened in Barendrecht? Case study on the planned onshore carbon dioxide storage in Barendrecht, the Netherlands, ECN and Global CCS Institute. http://admin.cottoncrc.org.au/files/ files/pybx.pdf.

Farquharson, K., 2003. Influencing Policy Transnationally: Pro-and Anti-Tobacco Global Advocacy Networks Australian. Journal of Public Administration 62 (4), $80-92$.

Fleck, 1979. The Genesis and Development of a Scientific Fact. University of Chicago Press, Chicago.

Gamson, W.A., Modigliani, A., 1989. Media discourse and public opinion on nuclear power: a constructionist approach. The American Journal of Sociology 95, 1-37.

Global CCS Institute, 2009. An Ideal Portfolio of CCS Projects and Rational for Supporting Projects, LEK Consulting.

Greenpeace International, 2008. False Hope, Why Carbon Capture and Storage Won't Save the Climate, Amsterdam.

Haas, P.M., 1992a. Introduction: epistemic communities and international policy coordination. International Organization 46 (1), 1-35.

Haas, P.M., 1992b. Banning chlorofluorocarbons: epistemic community efforts to protect stratospheric ozone. International Organization 46 (1), 187-224

Hansson, A., Bryngelsson, M., 2009. Expert opinions on carbon dioxide capture and storage-a framing of uncertainties and possibilities. Energy Policy 37 (6), 2273-2282.
Hekkert, M.P., Suurs, R.A.A., Negro, S.O., Kuhlmann, S., Smits, R., 2007. Functions of innovation systems: a new approach for analysing technological change. Technological Forecasting and Social Change 74 (4), 413-432.

Hultman, N.E., Koomey, J.G., 2007. The risk of surprise in energy technology costs. Environmental Research Letters 2 .

IEA, 2008. $\mathrm{CO}_{2}$ Capture and Storage-A Key Carbon Abatement Option. International Energy Agency, 266 pp.

IJGGC, 2010. The International Journal of Greenhouse Gas Control. http:// journals.elsevier.com/17505836/international-journal-of-greenhouse-gascontrol/ (2010-12-15).

IPCC, 2005. IPCC Special Report on Carbon Dioxide Capture and Storage, Summary for Policymakers, Intergovernmental Panel on Climate Change, Working Group III.

IPCC, 2007. Mitigation of Climate Change, Working Group III Report, Intergovernmental Panel on Climate Change.

Kasperson, J.X., Kasperson, R.E., Perkins, B.J., Renn, O., White, A.L., 2005. Media risk signals and the proposed yucca mountain nuclear waste repository, 1985-1989. In: Kasperson, J.X., Kasperson, R.E. (Eds.), The Social Contours of Risk. Earthscan, London.

Keohane, R.O., 1989. International Institutions and State Power. Westview Press, Boulder, CO.

Lounsbury, M., Glynn, M.A., 2001. Cultural entrepreneurship: stories, legitimacy, and the acquisition of resources. Strategic Management Journal $22(6 / 7)$ 545-564.

Lovins, A.B., Sheikh, I., 2008. The Nuclear Illusion. Ambio, Nov 08 preprint draft.

Malone, E.L., Dooley, J.J., Bradbury, J.A., 2009. Moving from misinformation derived from public attitude surveys on carbon dioxide capture and storage towards realistic stakeholder involvement. International Journal of Greenhouse Gas Control 4 (2), 419-425.

Meadowcroft, J., Langhelle, O. (Eds.), 2009. Caching the Carbon: The Politics and Policy of Carbon Capture and Storage. Edward Elgar, Cheltenham, UK.

Miller, H.T., Fox, C.J., 2001. The epistemic community. Adminsitration and Society 32 (6), 668-685.

Nader, L., 1981a. Barriers to thinking new about energy. Physics Today 34 (9), 99-104.

Nader, L., 1981b. The politics of energy: toward a bottom-up approach. Radcliffe Quarterly 67, 5-6.

Newby-Clark, I., Ross, M., Buehler, R., Koehler, D., Griffin, D., 2000. People focus on optimistic scenarios and disregard pessimistic scenarios while predicting task completion times. Journal of Experimental Psychology: Applied 6, 171-182.

NyTeknik, 2009. Protester stoppar danskt $\mathrm{CO}_{2}$-lager (Protests stop Danish $\mathrm{CO}_{2}$ storage) http://www.nyteknik.se/nyheter/energi_miljo/energi/article583207.ece.

Ohnishi, T., 1998. Variation of public opinion regarding nuclear energy with the change of nuclear information by the media. Journal of the Atomic Energy Society of Japan 40 (7), 563-571.

Paterson, M., 1996. Global Warming and Global Politics. Routledge.

Reiner, D., 2008. A Looming Rhetorical Gap: A Survey of Public Communications Activities for Carbon Dioxide Capture and Storage Technologies. EPRG Working Paper 0801, European Commission FP6 ACCSEPT Project, http://www.electricitypolicy.org.uk/pubs/wp/eprg0801.pdf.

Reiner, D.M., et al., 2006. American exceptionalism? Similarities and differences in national attitudes toward energy policy and global warming. Environmental Science \& Technology 40 (7), 2093-2098.

Sabatier, P.A., Jenkins-Smith, H.C., 1993. Policy Change and Learning: An Advocacy Coalition Approach. Westview Press, Boulder, CO.

Sabatier, P.A., 1988. An advocacy coalition framework of policy change and the role of policy-oriented learning therein. Policy Sciences 21 (2), 129-168.

Shackley, S., et al., 2007. Stakeholder perceptions of $\mathrm{CO}_{2}$ capture and storage in Europe: results from a survey. Energy Policy 35 (10), 5091-5108.

Smil, V., 2000. Perils of long-range energy forecasting - reflections on looking far ahead. Technological Forecasting and Social Change 65, 251-264.

Stephens, J.C., Jiusto, S., 2010. Assessing innovation in emerging energy technologies: socio-technical dynamics of carbon capture and storage (CCS) and enhanced geothermal systems (EGS) in the USA. Energy Policy 38, 2020-2031.

Stephens, J.C., Wilson, E.J., Peterson, T.R., 2008. Socio-Political Evaluation of Energy Deployment (SPEED): an integrated research framework analyzing energy technology deployment. Technological Forecasting and Social Change 75, $1224-1246$.

Tjernshaugen, A., 2008. Political commitment to $\mathrm{CO}_{2}$ capture and storage: evidence from government RD\&D budgets. Mitigation, Adaptation, Strategy Global Change 13, 1-21.

Toke, D., 1999. Epistemic Communities and Environmental Groups. Politics 19 (2), 97-102.

van Alphen, K., Noothout, P.M., Hekkert, M.P., Turkenburg, W.C., 2010. Evaluating the development of carbon capture and storage technologies in the United States. Renewable \& Sustainable Energy Reviews 14, 971-986.

Van Noorden, R., 2010. Buried trouble. Nature 463, 871-873.

Wilson, E.J., Johnson, T.L., Keith, D.W., 2003. Regulating the ultimate sink: managing the risks of geologic $\mathrm{CO}_{2}$ storage. Environmental Science \& Technology 37 (16), 3476-3483.

Wong-Parodi, G., Ray, I., Farrell, A.E., 2008. Environmental non-government organizations' perceptions of geologic sequestration. Environmental Research Letters 3. (2).

Zimmerman, M.B., 1982. Learning effects and the commercialization of new energy technologies: the case of nuclear power. The Bell Journal of Economics 13 (2), 297-310. 